\title{
ПРЯМЫЕ ИНОСТРАННЫЕ ИНВЕСТИЦИИ И ВЛИЯНИЕ НА ЭКОНОМИКУ В ПРОВИНЦИИ ТХАЙНГУЕНЕ
}

\author{
(c) 2020 Нгуен Хюи Хоанг \\ аспирант \\ Финансовый университет при Правительстве Российской Федерации, Россия, Москва \\ E-mail: hoangg@mail.ru
}

Прямые иностранные инвестиции (ПИИ) внесли позитивный вклад в местное экономическое развитие провинции Тхайнгуена благодаря вкладу в экономический рост, реструктуризации экономики, доходам государственного бюджета и экспортным оборотам. Однако вклад ПИИ невелик по сравнению с масштабом, прибылью и объемом производства. На основании результатов исследования в статье предлагается ряд рекомендаций по дальнейшему усилению роли ПИИ в экономическом развитии в провинции Тхайнгуене.

Ключевые слова: экономическое развитие, инвестиция, прямые иностранные инвестиции, ПИИ.

Тхайнгуен - это провинция с благоприятными условиями для промышленного и социальноэкономического развития в настоящем и будущем. Для Тхайнгуена прямые иностранные инвестиции (ПИИ) являются важным ресурсом для развития экономики, так как это не просто капитал, они также сопровождаются передачей передовых технологий и управленческим опытом.

ПИИ стимулируют индустриализацию и модернизацию страны в сочетании с экономической институциональной реформой и экономической перестройкой. По состоянию на сентябрь 2016 года общее количество проектов с ПИИ во всей провинции составило 116 проектов с общим зарегистрированным инвестиционным капиталом 7.185,4 млн. долл. США.

Проекты с ПИИ ориентированы на такие основные области, как: производство электронных компонентов, мобильных устройств, электроники и телекоммуникаций; промышленное производство; производство экспортируемых ручных механических инструментов; производство одежды на экспорт; сборка электронных продуктов; печать промышленных этикеток.

\section{Положительные эффекты}

На рисунке 1 показан вклад ПИИ в темпы экономического роста благодаря вкладу в производство Тхайнгуена в период 2000-2017 гг. Если в период 2000-2003 гг. производство с ПИИ составляло только 7,93\% от общего производства провинции со средним значением 456,16 млрд. донгов, то в период 2016-2017 гг. на сектор ПИИ приходится $35,9 \%$ от общего объема производства с 25.728,05 млрд. донгов.

Экономическая перестройка является одной из важных целей в ориентировании устойчивого развития провинции Тхайнгуена до 2020 года. Структура экономики в предыдущем периоде провинции Тхайнгуена (Таблица 2) показывает, что цель экономической реструктуризации не была достигнута. Доля промышленности по-прежнему низка по сравнению с поставленной целью, в то время как сельское, лесное и

Таблица 1. Темпы экономического роста провинции Тхайнгуена (в \%)

\begin{tabular}{|c|c|c|c|c|}
\hline Период & Итого & $\begin{array}{l}\text { Сельское, лесное и } \\
\text { рыбное хозяйство }\end{array}$ & $\begin{array}{c}\text { Промышленность } \\
\text { и строительство }\end{array}$ & Услуги \\
\hline $\mathbf{2 0 0 0 - 2 0 0 3}$ & 0,08 & 0,03 & 0,29 & 0,05 \\
\hline $\mathbf{2 0 0 4 - 2 0 0 7}$ & 0,19 & 0,2 & 0,24 & 0,21 \\
\hline $\mathbf{2 0 0 7 - 2 0 0 9}$ & 0,22 & 0,18 & 0,24 & 0,25 \\
\hline $\mathbf{2 0 1 0 - 2 0 1 2}$ & 8,07 & 5,15 & 8,95 & 8,81 \\
\hline $\mathbf{2 0 1 3 - 2 0 1 5}$ & 22,97 & 7,12 & 45,03 & 8,97 \\
\hline $\mathbf{2 0 1 6 - 2 0 1 7}$ & 14,55 & 4,18 & 20,53 & 7,81 \\
\hline
\end{tabular}

Составлено автором на основе данных Главного статистического управления Вьетнама https://gso.gov.vn/default.aspx?tabid=716 
рыбное хозяйство по-прежнему составляет значительную долю экономики.

Тем не менее, период 2016-2017 гг. продемонстрировал заметные изменения в экономической структуре, когда доля промышленности и строительства составила почти $56 \%$, а сельское, лесное и рыбное хозяйство только около $11 \%$ ВВП провинции. Роль ПИИ в экономическом переходе в провинции Тхайнгуене показана значительным вкладом в быстрый рост сектора ПИИ в стоимости промышленного производства (Рис. 1).

Влияние ПИИ на экономику также оценивается по вкладу этого сектора в доходы государственного бюджета и экспортный оборот Тхайнгуена. Доходы госбюджета в провинции в последнее время начали значительно расти. Доходы бюджета в период 2013-2015 гг. увеличились в 34 раза по сравнению с общим доходом в период 2000-2003 гг.; в 17 раз выше, чем в сред- нем в период 2004-2006 гг., и в 11 раз выше, чем в период 2007-2009 гг. [2].

Статистические данные показывают, что объем инвестиций ПИИ, сделанных на рекордном уровне в период с 2014 года по настоящее время, также способствует значительному росту экспорта провинции. Объем экспорта за период 2013-2015 гг. составил 11.625,9 млрд. донгов, что в 500 раз выше, чем средний показатель за период 2000-2003 гг. (23,06 млрд. донгов), и почти в 77 раз превышает средний экспорт в 20102012 гг. [2].

Процесс инвестирования и осуществления проектов с ПИИ также оказывает влияние на стимулирование развития других секторов в провинции, поскольку во время строительства проекта используется большое количество строительных материалов, таких как: цемент, песок, камень и т.д.

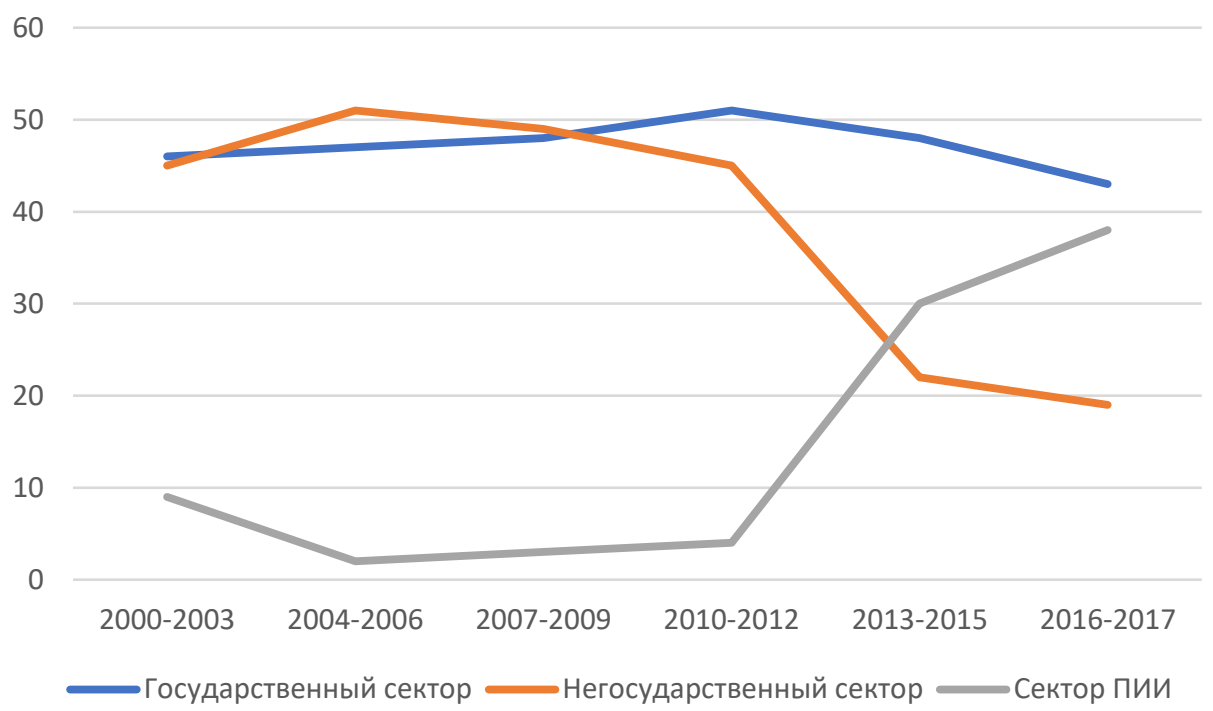

Рис. 1. Доля ПИИ в ВРП в\%

Составлено автором на основе данных Главного статистического управления Вьетнама https://gso.gov.vn/default.aspx?tabid=716

Таблица 2. Экономическая структура провинции Тхайнгуена в период 2000-2017 гг. (в \%)

\begin{tabular}{|c|c|c|c|c|}
\hline Период & Итого & $\begin{array}{l}\text { Сельское, лесное и } \\
\text { рыбное хозяйство }\end{array}$ & $\begin{array}{c}\text { Промышленность } \\
\text { и строительство }\end{array}$ & Услуги \\
\hline $\mathbf{2 0 0 0 - 2 0 0 3}$ & 100 & 33,11 & 42,03 & 24,86 \\
\hline $\mathbf{2 0 0 4 - 2 0 0 7}$ & 100 & 28,98 & 36,69 & 34,33 \\
\hline $\mathbf{2 0 0 7 - 2 0 0 9}$ & 100 & 24,98 & 39,00 & 36,02 \\
\hline $\mathbf{2 0 1 0 - 2 0 1 2}$ & 100 & 22,32 & 38,75 & 38,93 \\
\hline $\mathbf{2 0 1 3 - 2 0 1 5}$ & 100 & 22,18 & 36,01 & 41,81 \\
\hline $\mathbf{2 0 1 6 - 2 0 1 7}$ & 100 & 11,50 & 56,50 & 32,00 \\
\hline
\end{tabular}

Составлено автором на основе данных Главного статистического управления Вьетнама https://gso.gov.vn/default.aspx?tabid=716 


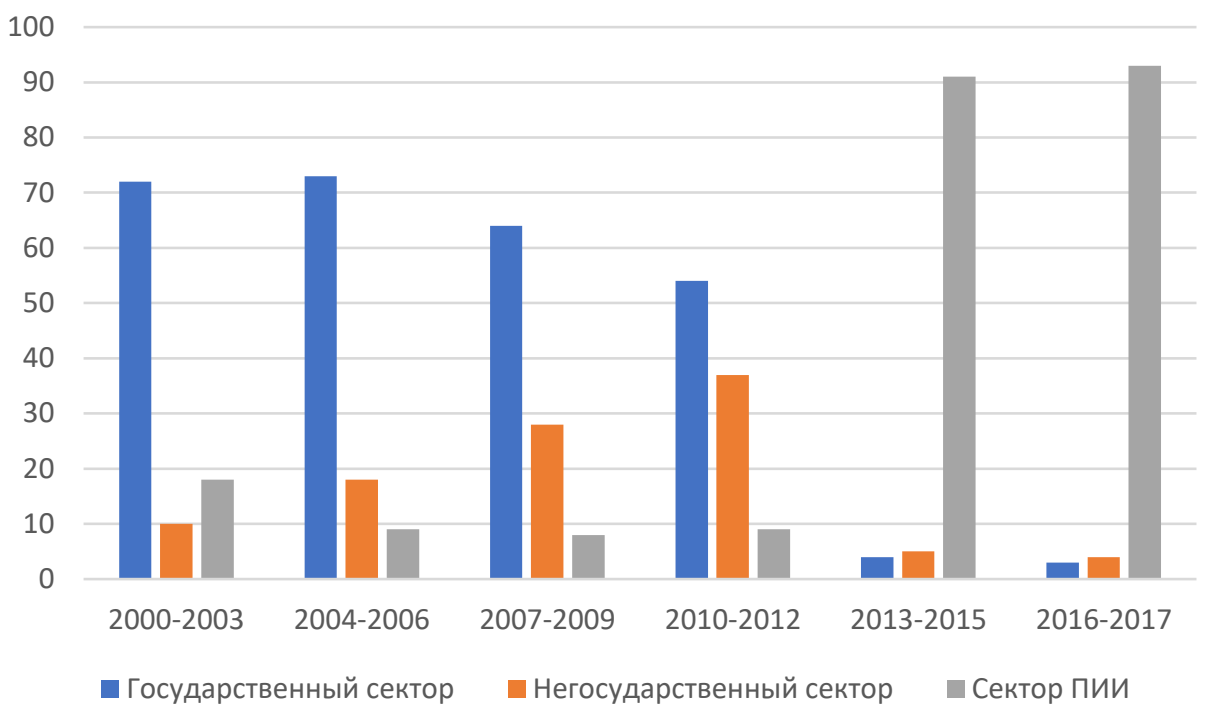

Puc. 2. Доля ПИИ в промышленности

Составлено автором на основе данных Главного статистического управления Вьетнама https://gso.gov.vn/default.aspx?tabid=716

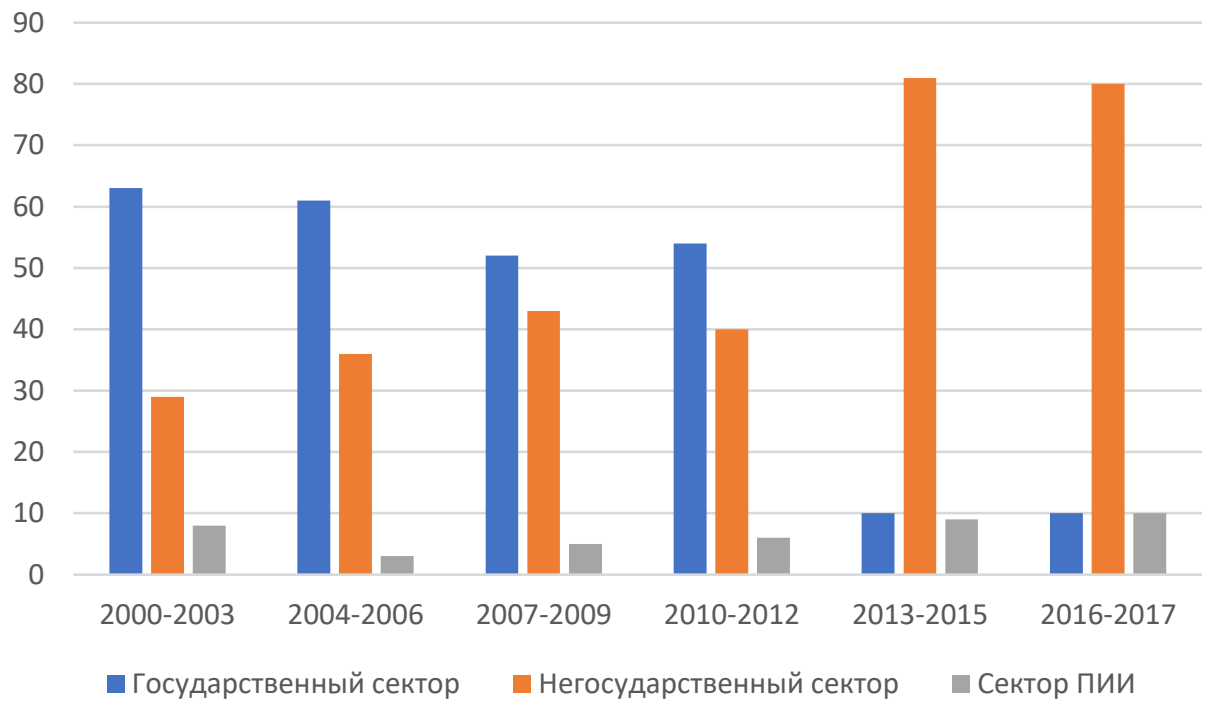

Puc. 3. Структура доходов государственного бюджета в провинции Тхайнгуене Составлено автором на основе данных Главного статистического управления Вьетнама https://gso.gov.vn/default.aspx?tabid=716

В проектах с ПИИ также использовалось большое количество продуктов и услуг, предоставляемых предприятиями Тхайнгуена. В частности, в Samsung работают 6 поставщиков промышленной гигиены, в том числе 2 поставщика из Тхайнгуена и 2 поставщика с филиалами в Тхайнгуене, в которых работают в общей сложности 3.960 человек, из них сотрудники Тхайнгуена составляют $76,2 \%$ (3.019 работников).

\section{Ограничения и недостатки}

Во-первых, вклад ПИИ слишком мал по сравнению с масштабом, прибылью и производственной стоимостью. Это связано с тем, что Samsung пользуется преференциальным режимом для высокотехнологичных предприятий, включая 4-летнее освобождение от уплаты корпоративного подоходного налога, право на ставку 5\% в течение следующих 9 лет и 10\% в течение оставшихся 17 лет проекта. Основной взнос государ- 
ственного бюджета Samsung составляют налог на доходы физических лиц, налог с подрядчиков и налог на добавленную стоимость, а корпоративный подоходный налог незначителен.

Во-вторых, возникает эффект перелива ПИИ. Хотя вклад ПИИ в доходы государственного бюджета в последние периоды увеличился, он по-прежнему слишком мал по сравнению с объемом производства. Например, согласно исследованию Академии социальных наук, в 2015 году Samsung получила прибыль в размере 3,1 млрд. долл. США (что эквивалентно более 65.000 млрд. донгов), но заплатила только 2.623 млрд. донгов в виде налогов в государственный бюджет (при текущей ставке $22 \%$ налоговый платеж составил бы приблизительно 13.000 млрд. донгов в 2015 году и более 20.000 млрд. донгов в 2016 году).

Вьетнамским работникам, работающим на Samsung, очень ограничена передача технологии. Они в основном учатся простым навыкам, которые вряд ли будут применены, если они больше не будут работать в Samsung.

\section{Предложения и рекомендации}

Результаты исследования показывают, что ПИИ вносят позитивный вклад в местное экономическое развитие. Однако вклад ПИИ слишком мал по сравнению с масштабом, прибылью и объемом производства; эффект перелива ПИИ остается одним из основных препятствий для провинции Тхайнгуена. Этот факт требует, чтобы Тхайнгуен продолжал оценивать эффективность инвестиций, влияние ПИИ на местное экономическое развитие, с тем чтобы дать эффективную ориентацию в привлечении ПИИ в социально-экономическое развитие провинции.

В частности, реализация стратегии привлечения ПИИ направлена на то, чтобы стать одним из ведущих мест привлечения ПИИ в период промышленной революции 4.0. Провинция Тхайнгуен должна активизировать административные реформы, повышать квалификации и навыков кадров; разработать ряд политик для привлечения инвестиций, повышения эффективности государственного управления и улучшения инвестиционной среды.

Тхайнгуен должен сосредоточиться на привлечении крупномасштабных проектов с ПИИ, особенно проектов в области информационных технологий; придавать большое значение развитию проектов с ПИИ в вспомогательных отраслях, машиностроении, обрабатывающей промышленности.

В то же время поддерживать и создавать благоприятные условия для предприятий с ПИИ для найма и использования рабочей силы в населенных пунктах провинции.

\section{Библиографический список}

1. Решение Премьер-министра № 260/QD-TTg от 27.02.2015 года «Об утверждении Генерального плана социально-экономического развития провинции Тхайнгуена до 2020 года и видения до 2030 года».

2. Департамент планирования и инвестиций. Сводный отчет о 30-летних иностранных инвестициях во Вьетнаме (2017).

3. Департамент промышленности и торговли. Результаты выполнения целевых задач в 2015, 2016, 2017 и основные решения для реализации запланированных целей на 2015, 2016, 2017 (2017).

4. Статистическое управление провинции Тхайнгуена. Статистический ежегодник провинции Тхайнгуена в период 2000-2017 годов (2017).

5. www.gso.gov.vn - Официальный сайт Главного статистического управления Вьетнама.

6. www.mpi.gov.vn - Официальный сайт Министерства планирования и инвестиций Вьетнама. 